\title{
COVID-19 UNCERTAINTY AND MONETARY POLICY RESPONSES: EVIDENCE FROM EMERGING MARKET ECONOMIES
}

\author{
K.P. Prabheesh* , Solikin M. Juhro** and Cicilia A. Harun*** \\ * Corresponding Author. Associate Professor, Indian Institute of Technology Hyderabad, India. \\ Email: prabheeshkp@gmail.com; prabheesh@iith.ac.in \\ ** Executive Director, Bank Indonesia, Indonesia. \\ *** Director, Bank Indonesia, Indonesia.
}

\begin{abstract}
This paper examines the effectiveness of monetary policy transmission in emerging economies during the COVID-19 pandemic. Using data from 14 emerging economies severely affected by the pandemic and the autoregressive distributed lag approach to cointegration, the study examines the effectiveness of monetary policy in affecting output, inflation, and credit. The study finds that: (1) in most economies, the monetary policy transmission to inflation is weakened due to the uncertainty created by the COVID-19 pandemic; (2) in a few economies, the transmission is found to be effective in stabilizing credit and output; and (3) the outbreak of the COVID-19 pandemic induced economic agents to follow a "cautionary" or "wait-and-see" approach.
\end{abstract}

Keywords: Monetary policy; Policy effectiveness; COVID-19; Pandemic; Uncertainty; Emerging economies.

JEL Classifications: E52; E58; E65.

\author{
Article history: \\ Received : July 03, 2021 \\ Revised : September 06, 2021 \\ Accepted : October 09, 2021 \\ Available Online: December 31, 2021 \\ https://doi.org/10.21098/bemp.v24i4.1692
}




\section{INTRODUCTION}

The uncertainty in the economy often interrupts the transmission process of monetary policy. As per the literature, during periods of uncertainty, monetary policies may not be effective because economic agents do not respond to policy changes due to the lack of precise information. Agents follow a 'wait and see' approach and postpone consumption or investment decisions until they acquire precise information about the economy (Aastveit et al., 2017). Therefore, the effectiveness of monetary policies is often questioned in the presence of elevated uncertainty. In this paper, we analyze the role of uncertainty on the effectiveness of the monetary policy responses of the Emerging Market Economies (EMEs) during the COVID-19 outbreak. We examined this issue due to the following reasons: (1) During the COVID-19 outbreak, the level of uncertainty increased to a level above that experienced during the global financial crisis in 2008-09 (see Fig. 1); (2) to mitigate the economic impact of the COVID-19 pandemic, central banks of the EMEs adopted an accommodative monetary policy, with varying degrees in several countries; and (3) the existing studies largely ignore how the uncertainty due to COVID-19 affected the monetary policy transmission in the EMEs. Thus, we hypothesize that monetary policy is not effective due to the uncertainty induced by COVID-19. The lockdowns and travel restrictions dampened the demand for goods and services, leading to a lack of incentive for the economic agents to respond to the policy rate changes, as they resort to fulfil basic needs (OECD,2020; Levin and Sinha, 2020; Wei and Han, 2020).

Figure 1.

Trends in VIX

This figure shows the trends in Chicago Board Options Exchange's CBOE Volatility Index, popularly known as VIX, an indicator of global uncertainty.

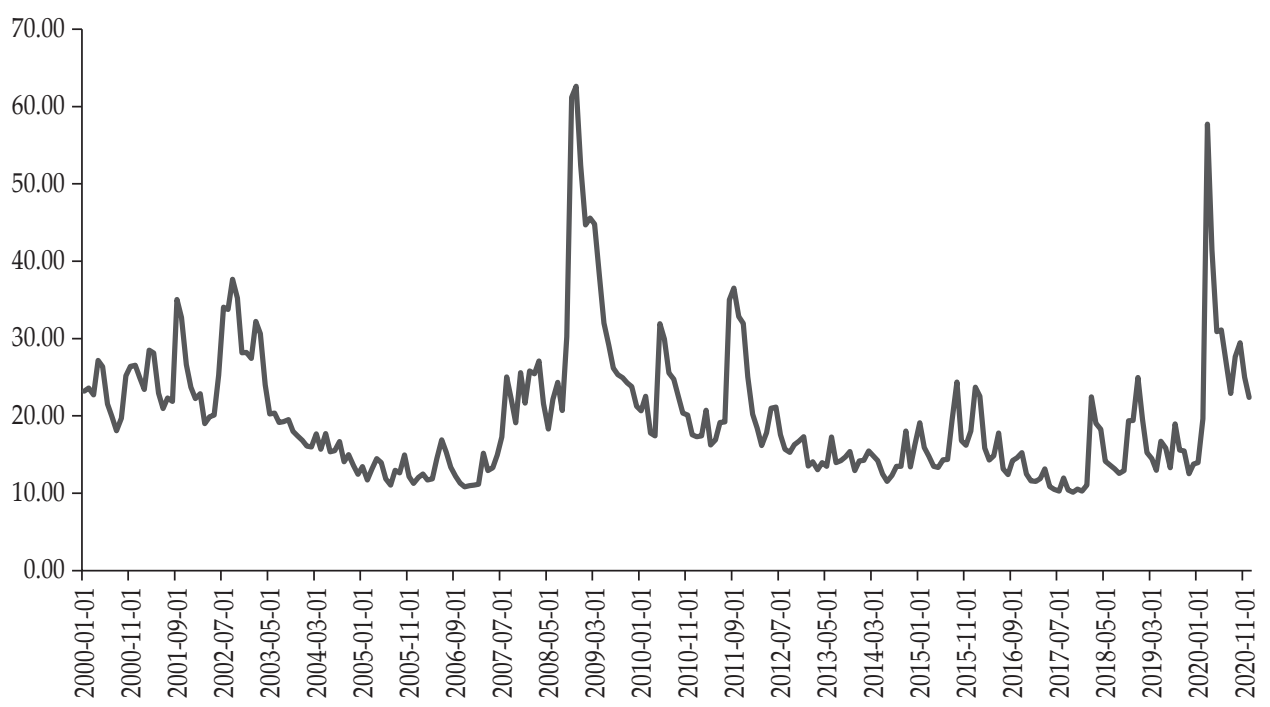


The existing research shows that uncertainty dampens monetary policy effectiveness compared to when monetary policy decisions are made under certainty (Martin and Milas, 2009; Ehrmann and Smets, 2003). The theory states that, in the presence of uncertainty, economic agents may prefer to 'wait and see' before investing due to the partial irreversibility of investments (Dixit and Pindyck, 1994; Bloom, 2009). Due to the cautionary effect of the uncertainty, economic agents do not spend or invest, but rather increase their precautionary savings. As precautionary savings play an important role in the stabilization process, its weak responsiveness to policy changes during uncertainty reduces the policy effectiveness. In such a scenario, it is argued that the policymakers must act aggressively to stabilize the economy (Aastveit et al., 2017). The evidence also suggests that the monetary authorities aggressively react under uncertainty (Giannoni, 2002; Sonderstrom, 2002). Similarly, the recent study by Pellegrino (2021) shows that accounting for uncertainty shocks would help important transmission channels and estimate the effects of an unexpected monetary stimulus in an accurate manner.

The studies on the economics of COVID-19 have been emerging in recent months. ${ }^{1}$ The studies related to monetary policy are largely confined to its effectiveness by measuring its impact on the stock market in North America, Africa, Asia, and Europe (Narayan et al., 2020; Phan and Narayan, 2020; Chundakkadan and Sasidharan), on the exchange rates in EMEs (Yilmazkuday, 2021), on long-term interest rates in the US (Bhar and Malliaris, 2021). Further, for the studies related to COVID-19 and its uncertainty relevels, uncertainty instantaneously affected the stock market (Haroon and Rizvi, 2020; Iyke and Ho, 2021; Li, 2021), exchange rates (Iyke, 2020a; Iyke, 2020b; Rai and Garg, 2021), oil market (Devpura and Narayan, 2020; Narayan, 2020), and trade and economic growth (Vidya and Prabheesh, 2020; Vidya, 2021; Zainuddin et al., 2021). However, none of these studies address how the uncertainty due to COVID-19 affected the monetary policy transmission in the case of the EMEs. Thus, the present study fulfils this research gap by examining the effectiveness of monetary policy actions of the central banks of EMEs during the uncertainty owe to COVID-19. Given the present multifaceted impact of the pandemic and the consequent uncertainty, it is important to examine the monetary policy's effectiveness to frame future policy actions.

Our approach to addressing these questions are as follows. (1) We select fourteen emerging economies, based on the severity of COVID-19 crisis. (2) We estimate three-time series models for each country, which include output growth, inflation, and credit growth as dependent variables, and interactive effect of the interest rate with the uncertainty measure as the independent variable. (3) We estimate these models using the Auto-Regressive Distributed Lagged (ARDL) method. (4) We also estimate these models using the Panel ARDL method, as a robustness test.

Our empirical findings show that: (1) the monetary policy transmission is weak in the presence of uncertainty during the COVID-19 period, especially in stabilizing output and inflation, whereas it is strong in the case of credit growth; and (2) the weak monetary policy transmission reveals the agents follow 'wait

${ }_{1}$ Refer Padhan and Prabheesh (2021); Narayan (2021) for review of papers related to economics of COVID-19. 
and see' approach during periods of high uncertainty. Our contributions to the existing literature are the following. First, this may be one of the first attempts to examine the effectiveness of monetary policy in the presence of uncertainty associated with COVID-19 in the context of emerging economies. Second, our findings have significant policy implications for the emerging markets in terms of conducting monetary policy during the uncertainty. The rest of the paper is organized as follows: section II presents the empirical model and data; Sections III and IV discuss the empirical methodology and findings; and Section V concludes.

\section{EMPIRICAL MODEL AND DATA}

A. Empirical Model

In this section, we construct an empirical model to examine the effectiveness of monetary policy in the presence of uncertainty. We analyse the responsiveness of key policy targets, such as output growth, inflation, and credit growth to the policy rate (interest rate). In the standard theory of monetary policy transmission mechanism, there are several transmission channels that can explain the effect of monetary policy on real sectors, or the development of the economy. Among others, there are channels that are perceived to work through the influence of central bank monetary policy instruments, such as the interest rate, credit supply, exchange rate, and expectations. Under normal or certain conditions, these channels will work differently, depending on the economic structure, market behaviour, and the feasibility of monetary policy instruments in conveying policy stances. However, in abnormal conditions, such as in the presence of the COVID-19 pandemic, only a few policy instruments can be properly utilised. The COVID-19 pandemic is an extraordinary event, so it requires extraordinary measures as well. In this regard, most central banks provide very large monetary stimulus packages, which are done, among others, by lowering interest rates, lowering the reserve ratio, and buying government bonds on the domestic money market (IMF, 2020). In this paper, we focus on the role of interest rates as the main instrument frequently utilized by central banks. The standard literature assumes that the monetary policy response through changes in policy interest rates will affect short-term interest rates in the money market, and subsequently affect deposit and lending rates, and ultimately the development of the economy.

The following models are estimated to address the research questions.

$$
\begin{aligned}
& \mathrm{Y}_{\mathrm{t}}=\beta_{0}+\beta_{1} i_{\mathrm{t}}+\beta_{2} V I X_{t}+\beta_{3} e r_{\mathrm{t}}+\varepsilon_{\mathrm{t}} \\
& \mathrm{Y}_{\mathrm{t}}=\beta_{0}+\beta_{1} i_{\mathrm{t}}+\beta_{2} V I X_{\mathrm{t}}+\beta_{3} e r_{\mathrm{t}}+\beta_{4}(\mathrm{i} * V I X)_{\mathrm{t}}+\varepsilon_{\mathrm{t}} \\
& \mathrm{Y}_{\mathrm{t}}=\beta_{0}+\beta_{1} \mathrm{i}_{\mathrm{t}}+\beta_{2} V_{\mathrm{VIX}}+\beta_{3} e r_{\mathrm{t}}+\beta_{4}\left(i * V I X_{t}\right)+\beta_{5}\left(i * V I X_{t} * \text { Covid_Dum }\right)+\varepsilon_{\mathrm{t}}
\end{aligned}
$$

where $Y_{t}$ includes (output growth, inflation, and credit growth). Similarly, $\beta_{1}, \ldots \beta_{5}$ are the parameters to be estimated. $\beta_{0}$ is the intercept; $t$ denotes time and $\varepsilon_{t}$ stands for error term. Likewise, $i$ denotes the policy rate, VIX stands for a measure of 
uncertainty and er stands for exchange rate. The Model (1) includes the basic variables, such as the interest rate, a measure of uncertainty, and exchange rate as a monetary control variable, whereas the Model (2) extends the basic model by including an interaction term $\left(i^{*} V I X_{t}\right)$ to examine the effectiveness of monetary policy in the presence of uncertainty. ${ }^{2}$ Similarly, in Model (3), we examine the impact of COVID-19 uncertainty on monetary policy effectiveness captured by triple interaction term $\left(i^{*} V I X_{t}^{*}\right.$ Covid_Dum $)$, where Covid_Dum stands for a dummy variable, which takes value 1 for the COVID-19 pandemic period and 0 for other periods. All variables in the models are expressed in logarithmic form, except the interest rate.

\section{B. Data}

We select 14 emerging economies, including Brazil, Chile, China, Colombia, Hungary, India, Russia , Malaysia, Mexico, Poland, Philippines, South Africa, Peru, and Turkey for the analysis. These countries are selected based on the severity of COVID-19 crisis (in terms of number of COVID-19 cases in EMEs) ${ }^{3}$ and availability of data. Monthly data for the period 2011M01-2020M09 related to the variables has been drawn from CEIC database and the Federal Reserve System's website. The dummy for COVID-19 varies with respect to the individual countries' responses to the COVID-19 outbreak. The response is drawn from the IMF's website. The output growth, inflation, and credit availability are proxied by the growth rate of the industrial production index, consumer price index, and banks' credit to the domestic sector, respectively. The interest rate $(i)$ is proxied by the lending rate ${ }^{4}$ and exchange rate (er) is the value of the country's currency for the purpose of conversion to US Dollar.

\section{METHODOLOGY}

\section{A. Autoregressive Distributed Lag Model (ARDL)}

Autoregressive Distributed Lag (ARDL) approach to cointegration, developed by Pesaran and Shin (1999) is employed to estimate the Models (1) to (3). It has advantages over the traditional cointegration techniques as it can be applied even with a mix of $\mathrm{I}(0)$ and $\mathrm{I}(1)$. The testing of the ARDL approach consists of two steps. The first step is to check the existence of a long-run cointegration relationship among variables. If cointegration is established, the second step is to estimate the long- and short-run coefficients using Error Correction Models (ECM). If the cointegration is rejected, the second step converges to the estimation of short-run coefficients only. The ECM form of ARDL Model (1) is given as follows:

2 We include an interaction term because the effect of interest rates on macroeconomic activity (either directly or via its impact on financial markets) can diver beyond standard theory, depending on uncertainty of macroeconomic nature.

3 https://www.worldometers.info/coronavirus/\#countries.

4 It is assumed that the monetary policy response through changes in the policy rate will affect shortterm interest rates on the money markets, and subsequently affect deposit and lending rates. 


$$
\begin{aligned}
& \Delta Y_{t}=\alpha_{0}+\beta_{1} Y_{t-1}+\beta_{2} i_{t-1}+\beta_{3} V I X_{t-1}+\beta_{4} e r_{t-1}+\sum_{I=1}^{P} \delta_{1} \Delta Y_{t-i}+ \\
& \sum_{I=1}^{P} \gamma_{1} \Delta i_{t-i}+\sum_{I=1}^{P} \varphi_{1} \Delta V I X_{t-i}+\sum_{I=1}^{P} \theta_{1} \Delta e r_{t-i}+\varepsilon_{t}
\end{aligned}
$$

The first part of the right-hand side $\beta$ values are the long-run coefficients and the second part with the parameters $\delta, \gamma, \varphi$, and $\theta$ are the short-run dynamics of the model. To obtain the long-run relationship we conducted the $F$-test of for the joint significance of the coefficients as $H_{0}=\beta_{1}=\beta_{2}=\beta_{3}=\beta_{4}=0$ against $H_{1}=\beta_{1}, \ldots \beta_{4} \neq 0$. Rejection of the null hypothesis represents the existence of cointegration. Pesaran and Shin (1999) proposed lower and upper critical values for the F-statistic assuming all variables are $\mathrm{I}(0)$ for lower bound and all are I(1) for upper bound. If the calculated $F$-statistic exceeds the upper critical value, then there is evidence of cointegration, whereas is fall below then the evidence of cointegration is rejected. However, if the calculated value falls between the lower and upper critical values, then the result is inconclusive. Once the cointegration is established, then the long- and short-run estimates can be calculated using vector error correction framework. As ARDL assumes no serial correlation, an appropriate lag length $(\mathrm{m})$ should be considered. We estimate the ARDL model based on the Akaike's information criterion.

\section{B. Panel ARDL Pooled Mean Group (PMG) Approach}

As a robustness test, we also use the panel ARDL econometric technique proposed by Pesaran et al. (1999) to estimate the models. We used the Pooled Mean Group (PMG) technique in the ARDL framework as it allows constant term, error variance, and short-run parameters to vary among panel countries. However, it assumes that the coefficients of the long-run relationship are constant across countries. The PMG estimator considers both pooling due to the homogeneity constraints on the long-run coefficients and averaging across countries to obtain the means of the estimated values of the error correction coefficients and short-run coefficients of the model. The PMG estimator computes the coefficients by using the NewtonRaphson algorithm. The coefficients obtained by PMG estimator are consistent and asymptotically normally distributed. This model includes both pooling and averaging techniques; therefore, it has an advantage over dynamic ordinary least square and fully modified least square methods.

As per the Pesaran et al., (1999), a panel regression can be written using ARDL $(p, q)$ approach, where $p$ is the lags of the dependent variable and $q$ is the lags of regressors. In equation form, this can be described as follows:

$$
y_{i}=\sum_{J=1}^{p-1} \sigma_{i j} y_{i t,-j}+\sum_{J=0}^{q-1} \tau_{i j} X_{i,-j}+\mu_{i}+\varepsilon_{i t}
$$

where $i=1,2, \ldots, 14$, is the number of countries in the panel; $t=1,2,3, \ldots, N$ denotes the time period; $y_{i}$ is a $(k \times 1)$ vector of dependent variables consisting of credit growth rate, inflation rate, output growth; $X_{i}$ is a matrix of the independent variables of order $(T \times k)$, which includes monetary policy, uncertainty index, exchange rate, and an interaction term between MP and uncertainty index and dummy variable; 
the variable $\mu_{i}$ is fixed effects, and $\varepsilon_{i}$ is a error term. If the variables Equation (5) were co-integrated then the residual term should follow $\mathrm{I}(0)$ order in order to have long-run relationship. Now we reparameterize Equation (5) to incorporate the error correction equation.

$$
\Delta y_{i t}=\eta_{i}\left(y_{i,-1}-\alpha^{\prime} X_{i t}\right)+\sum_{J=1}^{p-1} \sigma_{i j}^{*} \Delta y_{i t,-j}+\sum_{J=0}^{q-1} \beta_{i j}^{*} X_{i,-j}+\mu_{i}+\varepsilon_{i t}
$$

where:

$$
\begin{aligned}
& \eta_{i}=-\left(1-\sum_{j=1}^{p} \lambda_{i j}\right), \quad \alpha_{i}=\frac{\sum_{j=0}^{q} \delta_{i j}}{\left(1-\sum k \lambda_{i k}\right)^{\prime}}, \sigma_{i j}^{*}=-\sum_{m=j+1}^{p} \lambda_{i m \prime} \\
& J=1,2, \ldots, p-1, \text { and } \beta_{i j}^{*}=-\sum_{m=j+1}^{p} \delta_{i m}, j=1,2,3, \ldots q-1 .
\end{aligned}
$$

The $\eta_{i}$ represents the speed of adjustment parameter; $\alpha_{i}$ are the long-run coefficients, $\sigma_{i j}{ }^{*}$ are the short-run coefficients of the dependent variables, $\beta_{i j}{ }^{*}$ are short-run coefficients of the independent variables.

\section{EMPIRICAL FINDINGS}

Before estimating the models, we investigate the unit root properties of the variables of each country by applying standard unit root tests, such as the Augmented Dickey-Fuller and Philips-Perron tests. As the overall findings suggest mixed order of the integration of the variables, that is, $\mathrm{I}(0)$ and $\mathrm{I}(1)$, we can employ the ARDL approach to cointegration for estimation. ${ }^{5}$

\section{A. Findings from ARDL Analysis}

We estimate 14 models for each country in the sample; the long-run cointegrating vector from the ARDL model for each country is reported from Table 1-14. The F-statistics reported in the bottom part of the table are found to be statistically significant and thus establishes the cointegrating relationship between the variables in the model. However, in some cases, cointegration is not found, and thus longrun estimates are not reported. The findings suggest that the domestic interest rate (i) is negative and statistically significant in the credit growth equation in Brazil, Mexico, Russia, the Philippines, and Chile, indicating an increase in interest rate reduces credit growth in the economy. These findings indicate an effective monetary policy in stabilizing credit growth. In comparison, the interest rate is found to stabilize the output in Brazil, Russia, Turkey, the Philippines, Hungary, and Chile. The findings also reveal that monetary policy effectively stabilizes inflation in the case of Brazil and Turkey.

It is also important to see that the uncertainty measure VIX has a positive and significant impact on credit growth in Chile, China, Colombia, and Mexico.

\footnotetext{
5 As there are 14 tables associated with the unit root test, but we do not include them in the text. However, these results are available upon request.
} 
It is also interesting to note that VIX significantly reduces output growth in most economies (i.e., 9 out of 14 economies). This finding underscores the destabilizing role of uncertainty on output. The variable VIX is also found to have an inflationary effect on Mexico and Malaysia.

It is also interesting to see that the exchange rate (er) exhibits a negative sign and is statistically significant in 5 cases. This indicates that an increase in the exchange rate, i.e., depreciation of the domestic currency, reduces credit growth, or an appreciation of the domestic currency increases credit growth. The negative link represents the balance sheet channel that can be attributed to the risk-taking behavior of the financial institutions in response to the exchange rate variations. For instance, during the exchange rate appreciation, the financial institutions borrow more from the international markets and accelerate the lending in the domestic market. This is mainly because domestic currency appreciation reduces the foreign liabilities and thus strengthens their balance sheet. Similarly, a negative relationship between exchange rate and inflation and the exchange rate and output growth can also be observed in most cases. This negative relationship further indicates that the exchange rate affects inflation and output through the risk-taking behavior of financial institutions.

However, in the case of the effect of monetary policy during the uncertainty, the results suggest that the interaction variable $\left(i^{*} V I X\right)$ is negative and statistically significant in the credit growth equation only in 3 out of 14 countries, i.e., Brazil, Peru, and South Africa, whereas, in the output equation, the interaction term is only negative and significant in India and Turkey. In Colombia, Malaysia, and Poland, the interaction term exhibits a positive sign and significance, indicating monetary policy is not effective during the period of uncertainty. For the inflation equation, the interaction term is negative and significant only in the case of Brazil and Turkey.

Finally, the triple interaction term, which captures the effect of uncertainty due to the COVID-19 pandemic, suggest that the monetary policy transmission is effective only in 5 out of 14 economies, i.e., Hungary (credit growth), Philippines (output growth), Turkey (credit growth), South Africa (credit and output). It is only important to note that none of the triple interaction terms are significant in stabilizing inflation. The lack of statistical significance of the triple interaction term in most of the EMEs clearly suggests that monetary policy transmission is weakened during the COVID-19 induced uncertainty period.

Overall, it can be concluded that the emergence of the COVID-19 pandemic, which created extreme uncertainty, has caused the ineffectiveness of the monetary policy transmission of interest rate to inflation in most EMEs. However, in a few EMEs, the transmission is found to be effective in stabilizing credit and output. These findings indicate that the outbreak of the COVID-19 pandemic induce economic agents to follow a "cautionary" or 'wait and see' approach until they gain better information, making them less responsive to changes in monetary policy. 


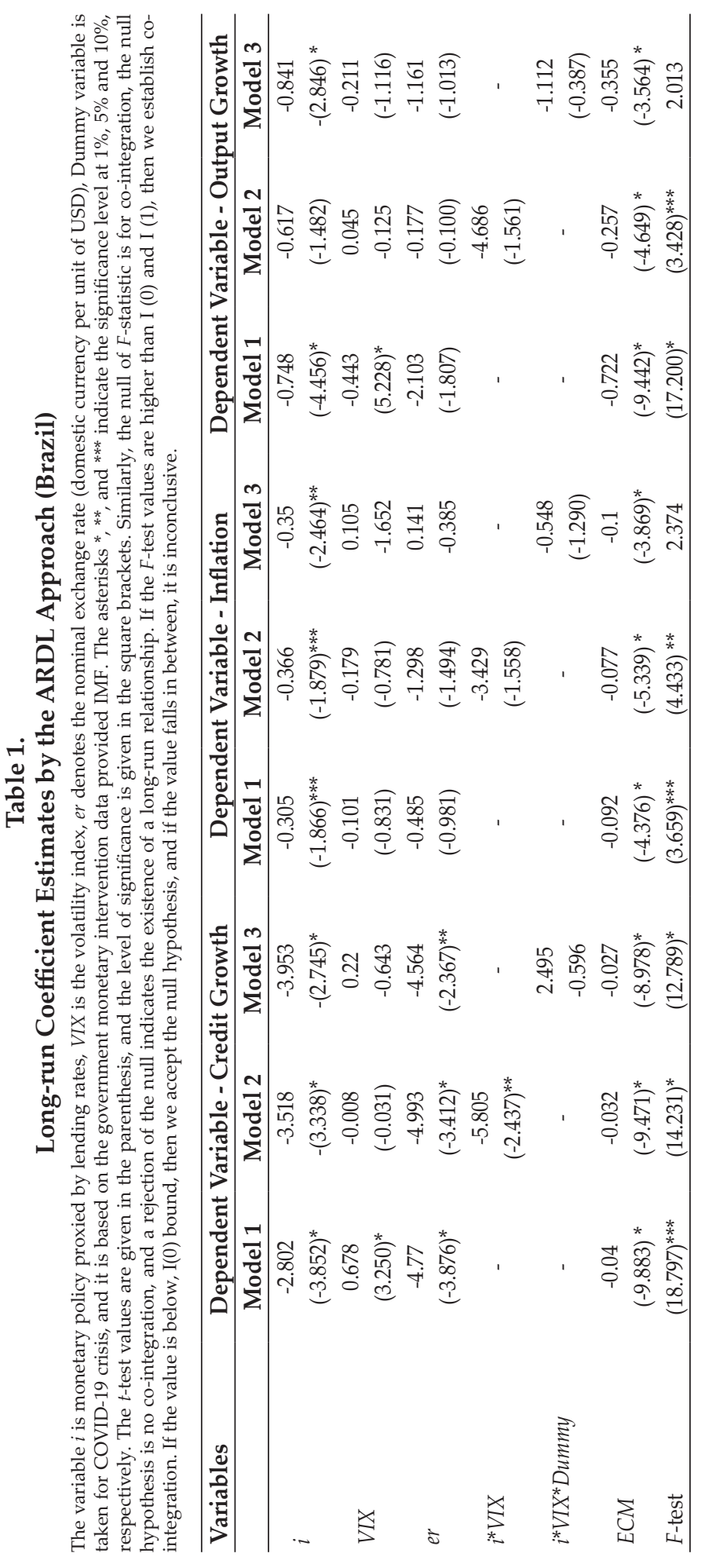


ڤิ)

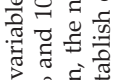

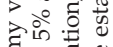

至 $0 \overbrace{}^{\circ}$

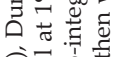

किष्ठ

웅

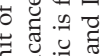

苯: 节

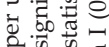

究㟔至

苋泀泀

굴

ฮ

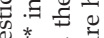

हैं

进舟

范范若

ह

군

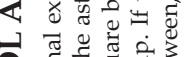

穴距

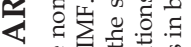

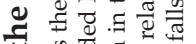

i

o $: \approx$

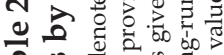

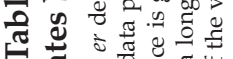

元

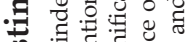

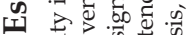

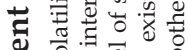

-

证要

ن \& $\overrightarrow{0}$

इ के

吕

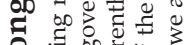

어

छ

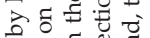

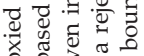

它.

卷范

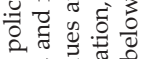

눈.

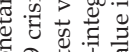

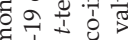

官号

令的出

U 용

总总密

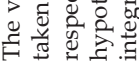

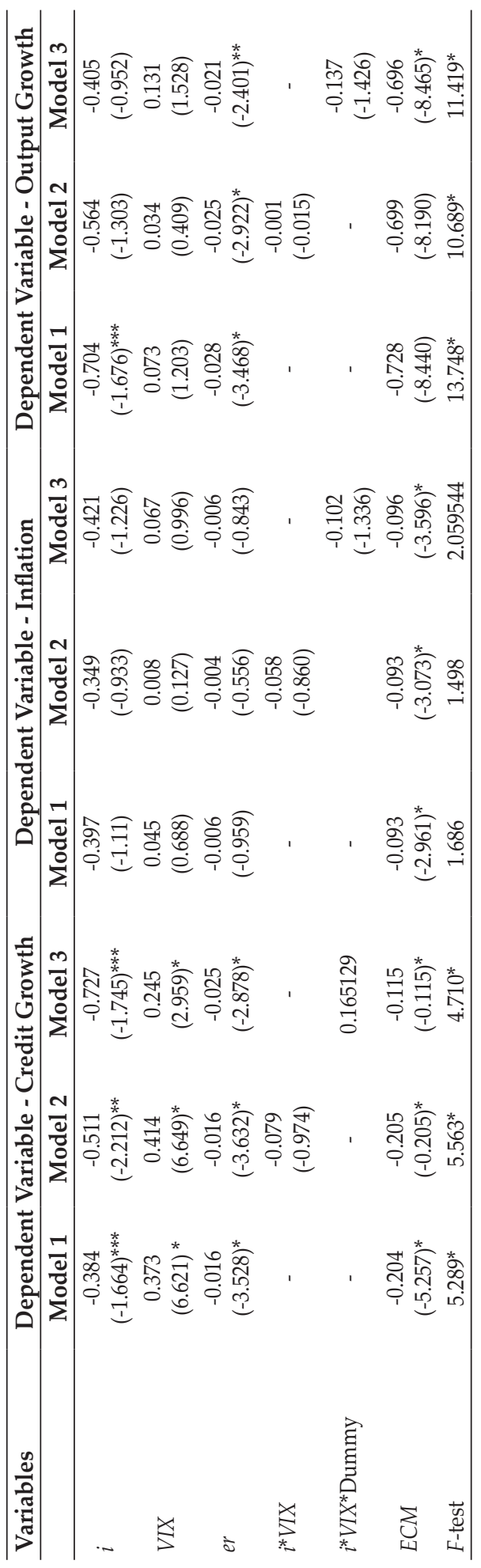




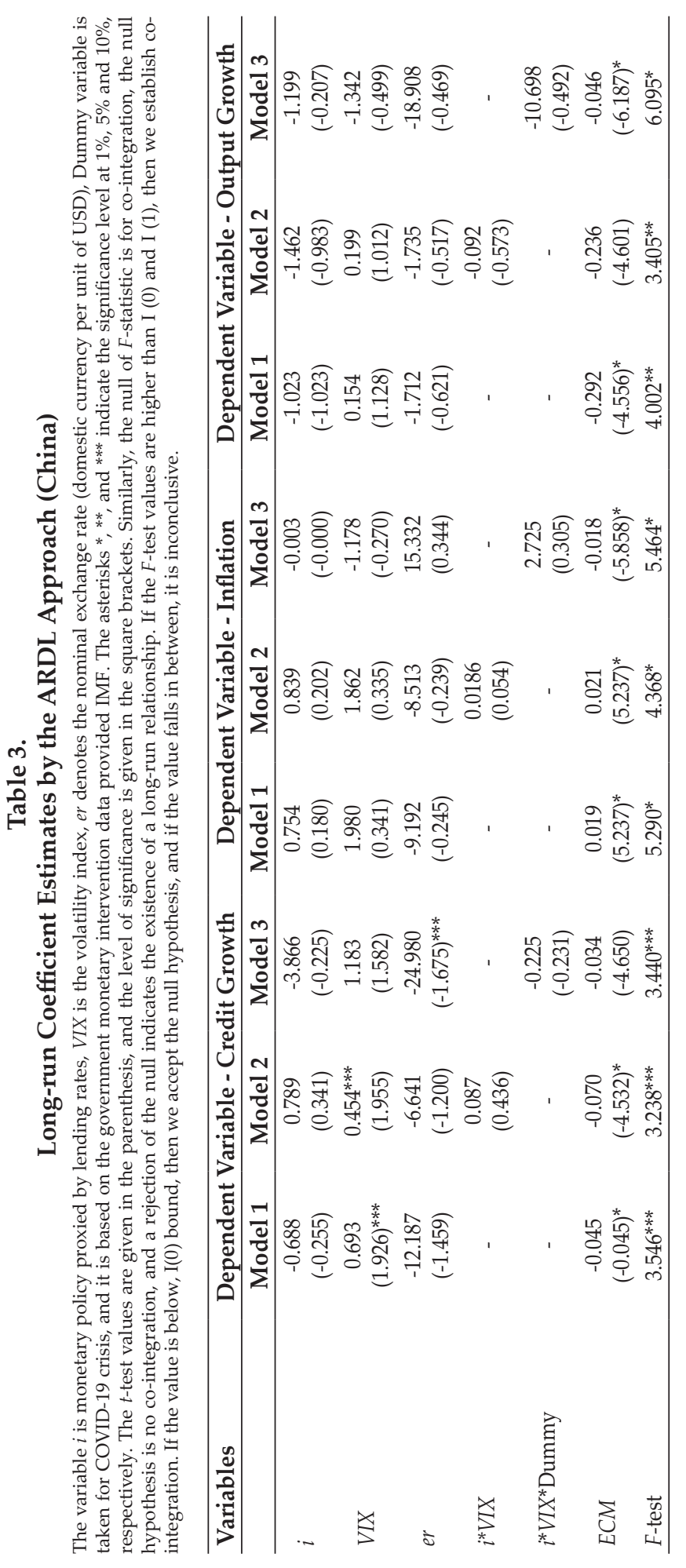




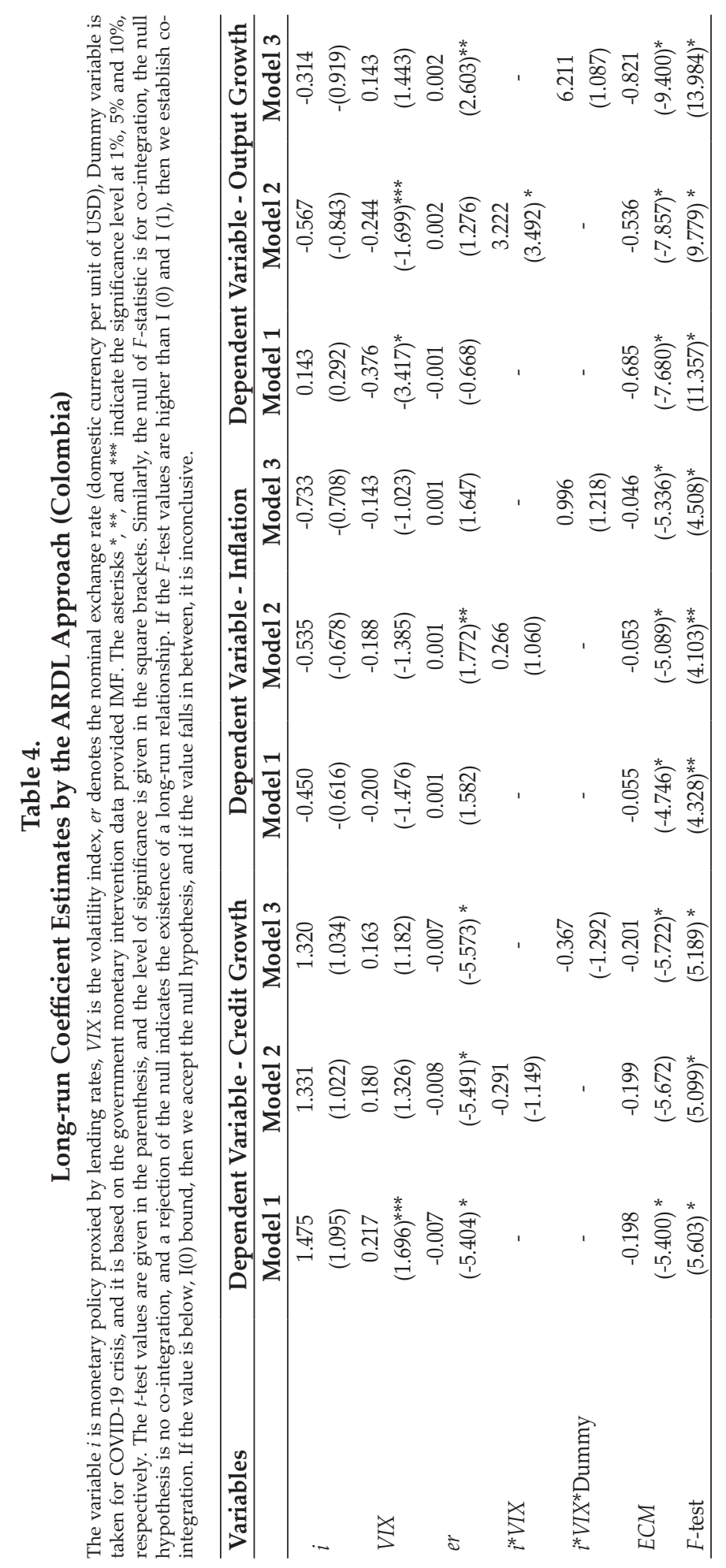




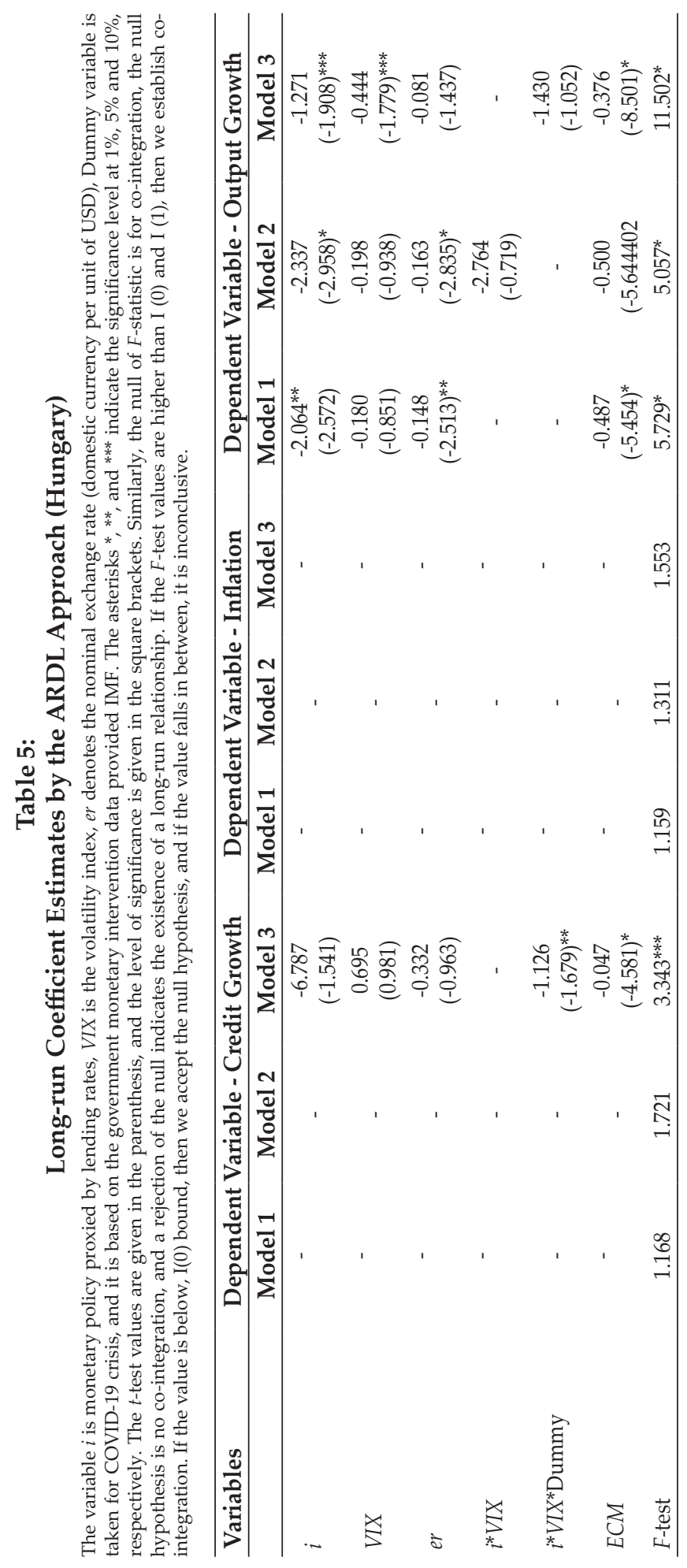




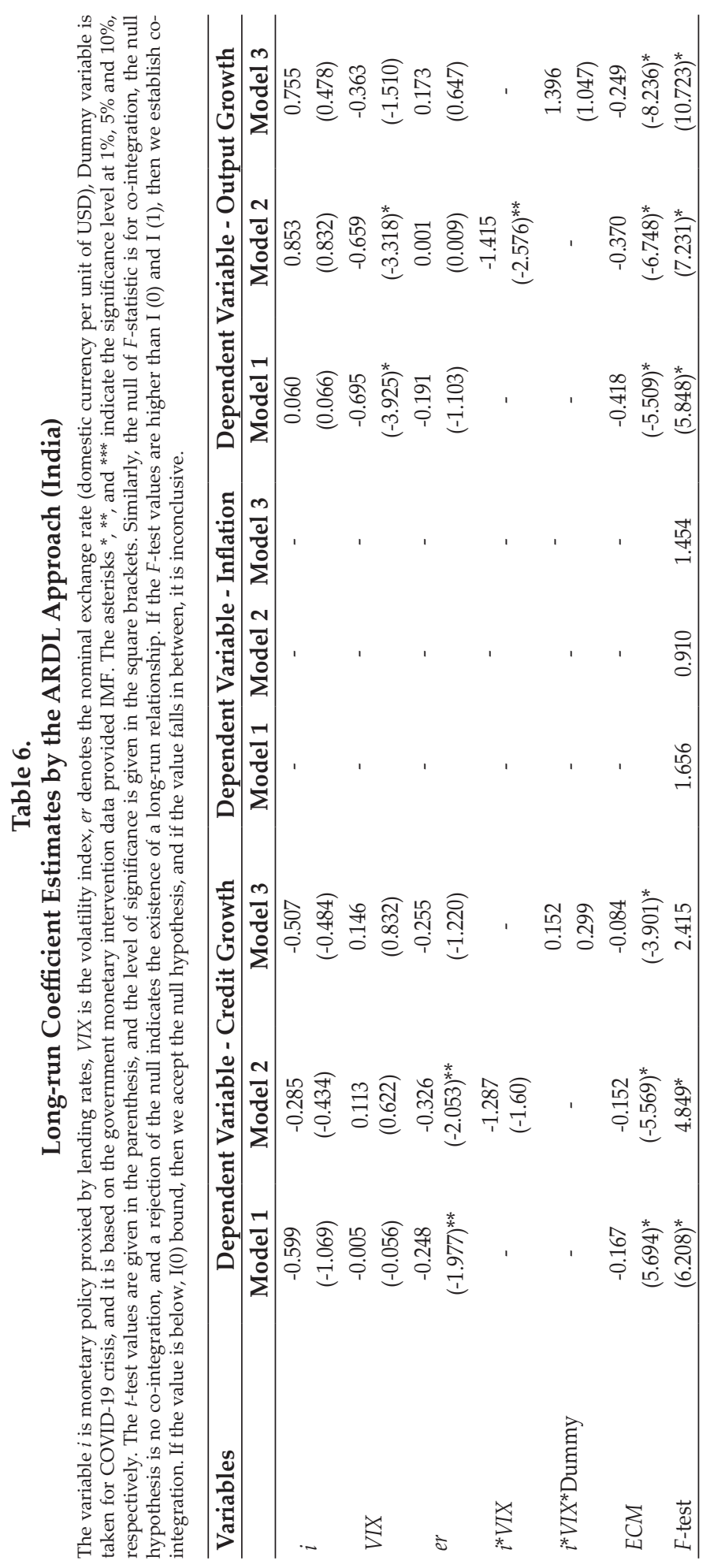




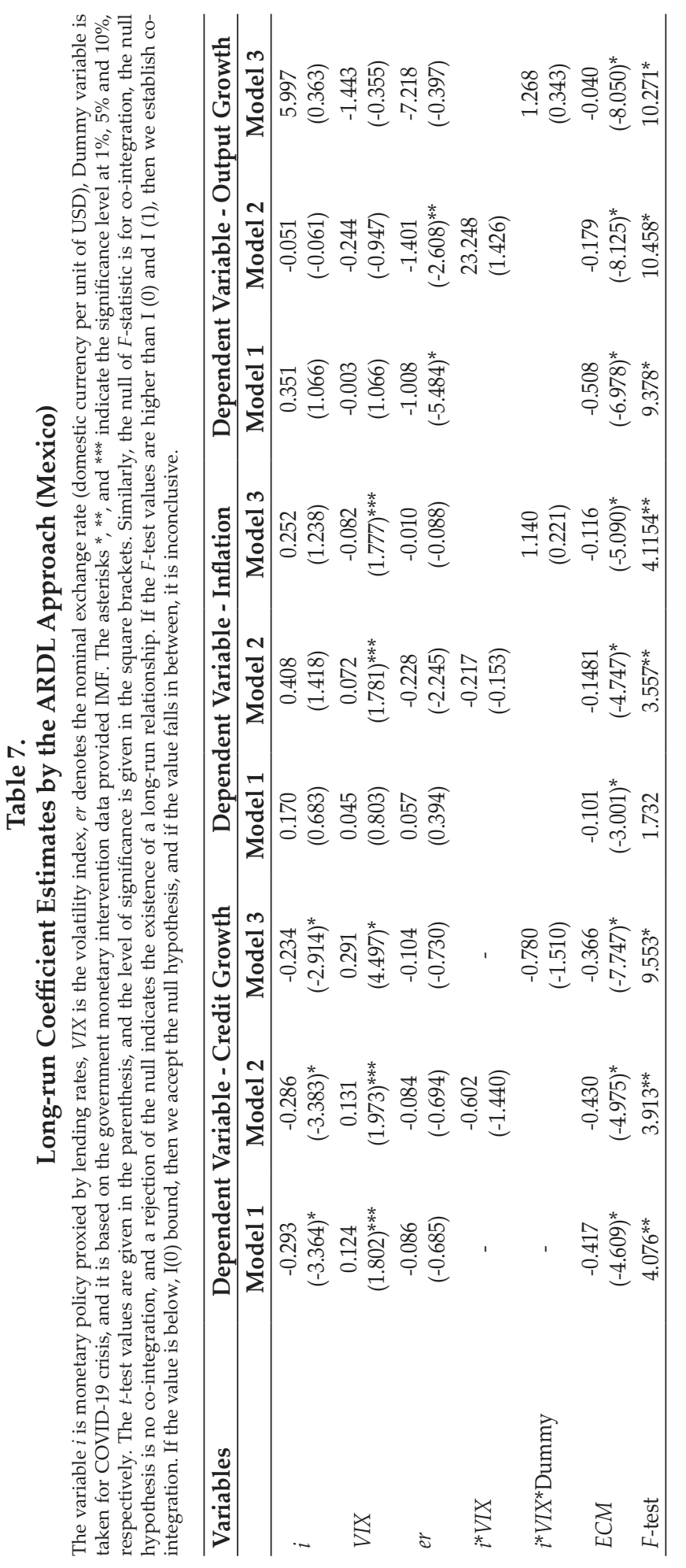




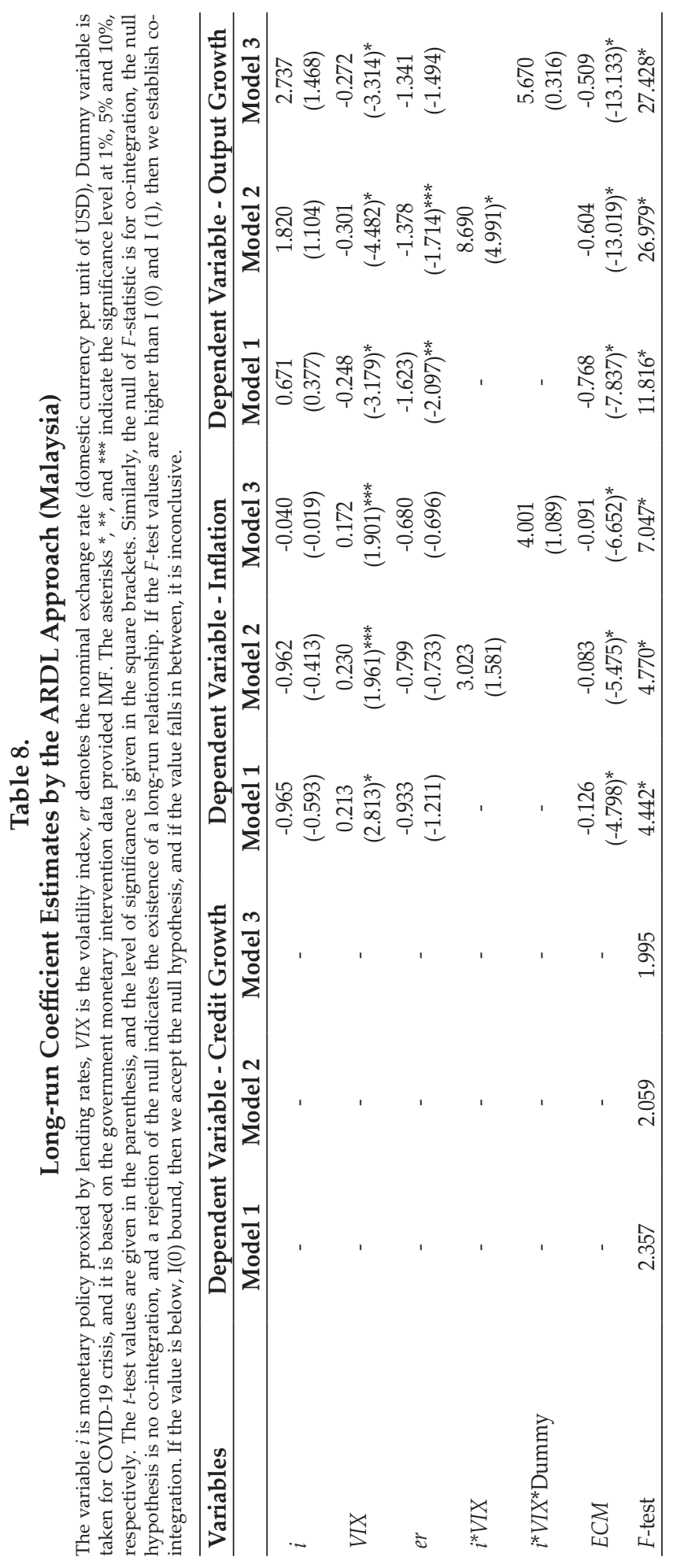




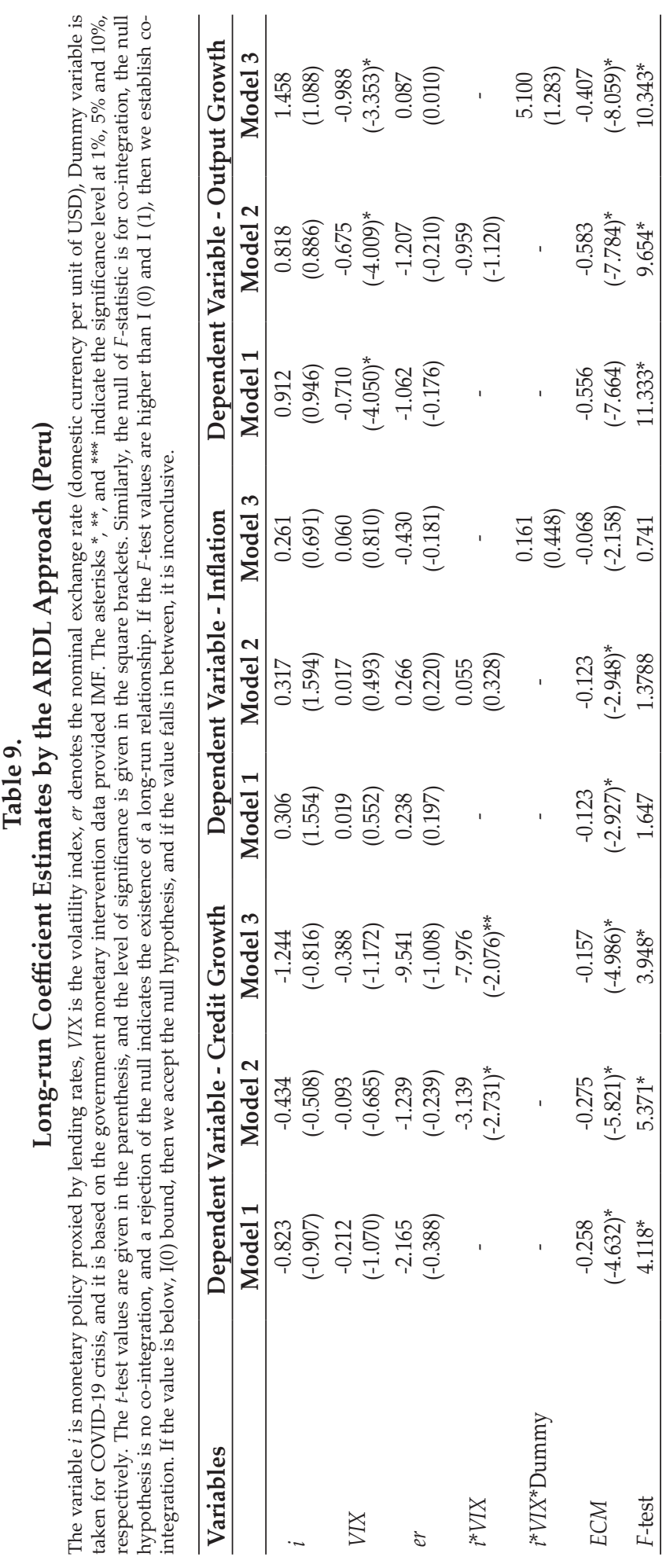




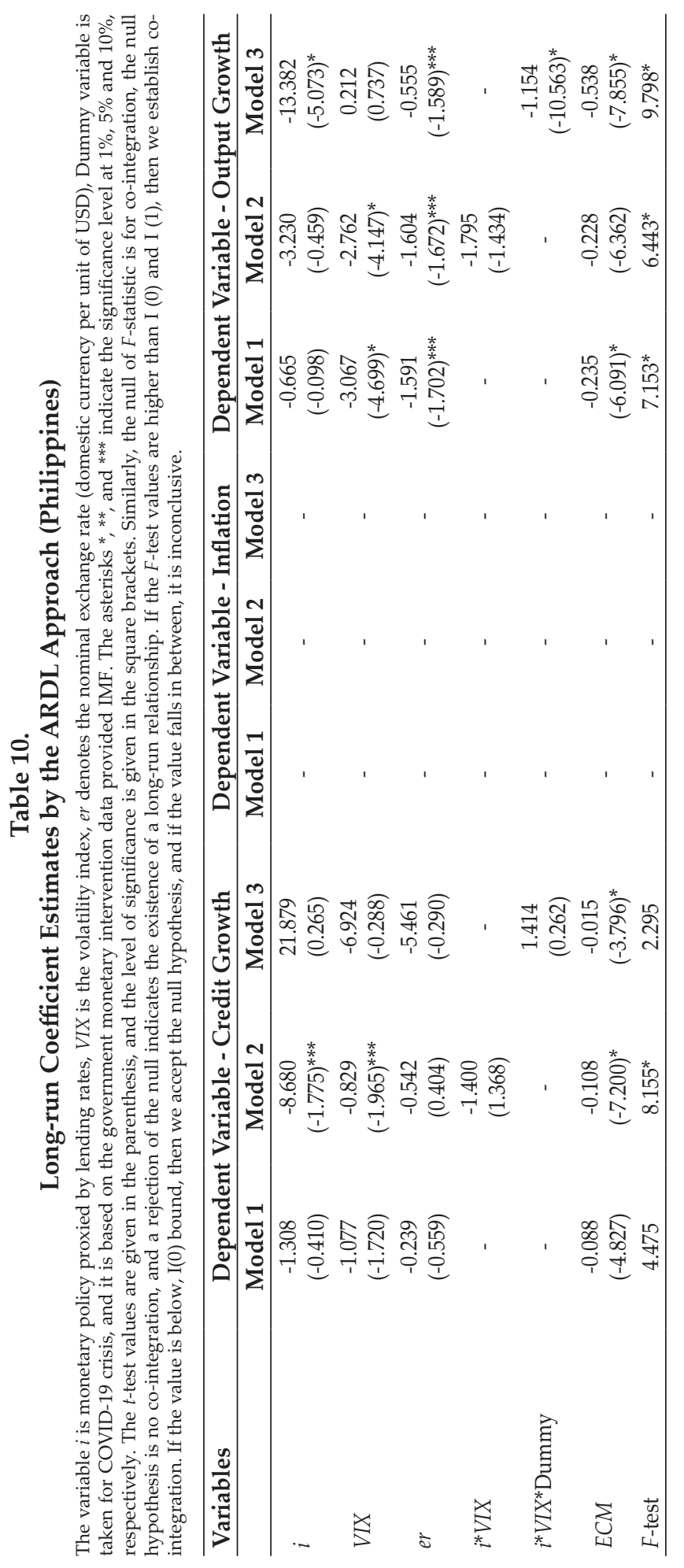




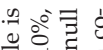

돈

का

ㅇํํ क्ष

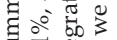

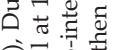

की 80

웡

듀 휴 휴

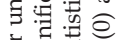

㟧些

它岕 至

要

¿ิ

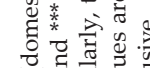

㖊

氜芯的苟

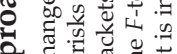

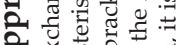

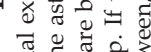

司丞

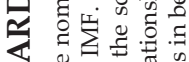

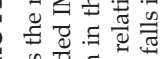

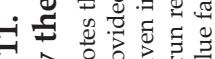

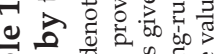

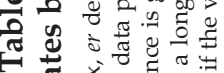

๘

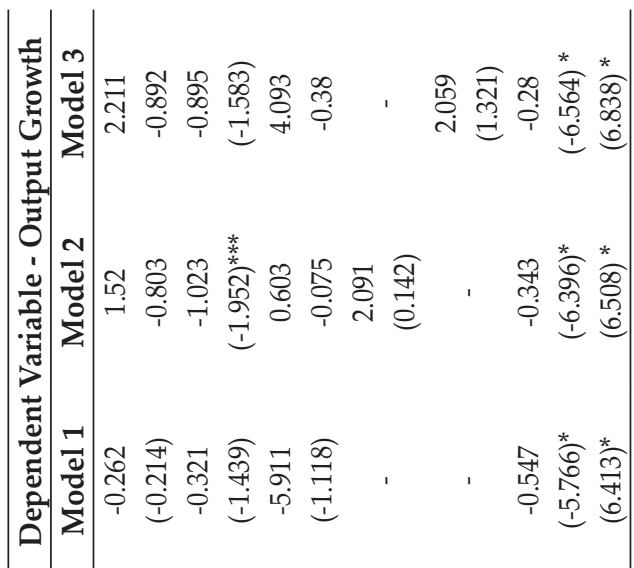

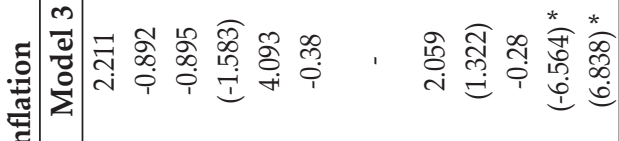

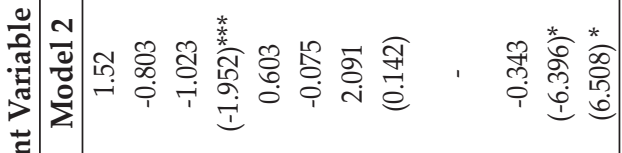

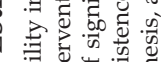

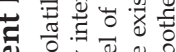

记

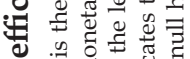

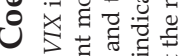

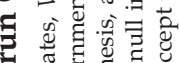

占

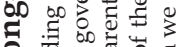

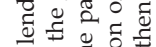

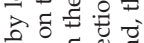

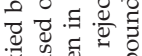

ธ。

2.

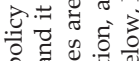

․․ ⿷匚

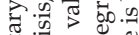

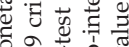

구 18

官导串

의의

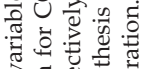

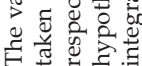

ڤั

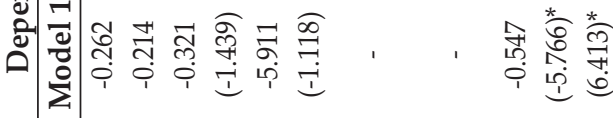

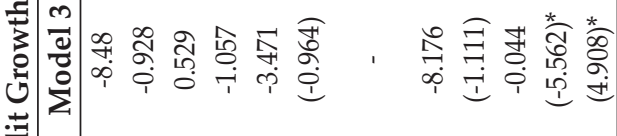

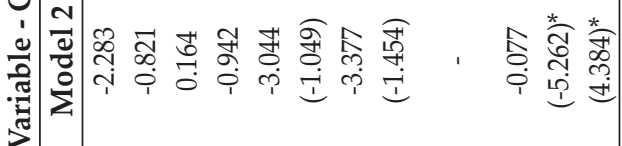

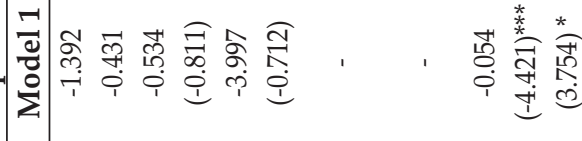

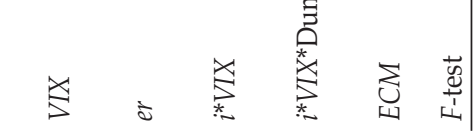




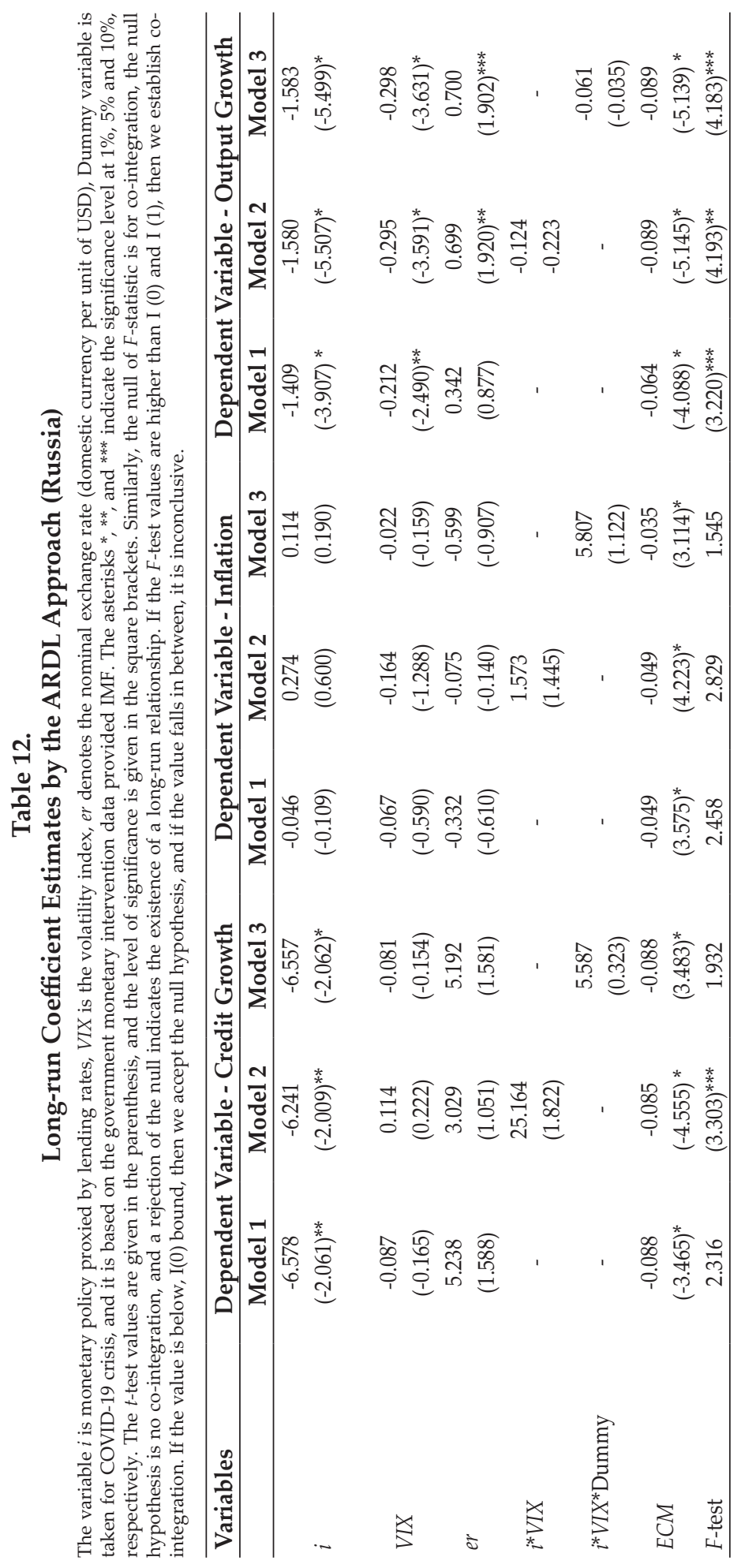




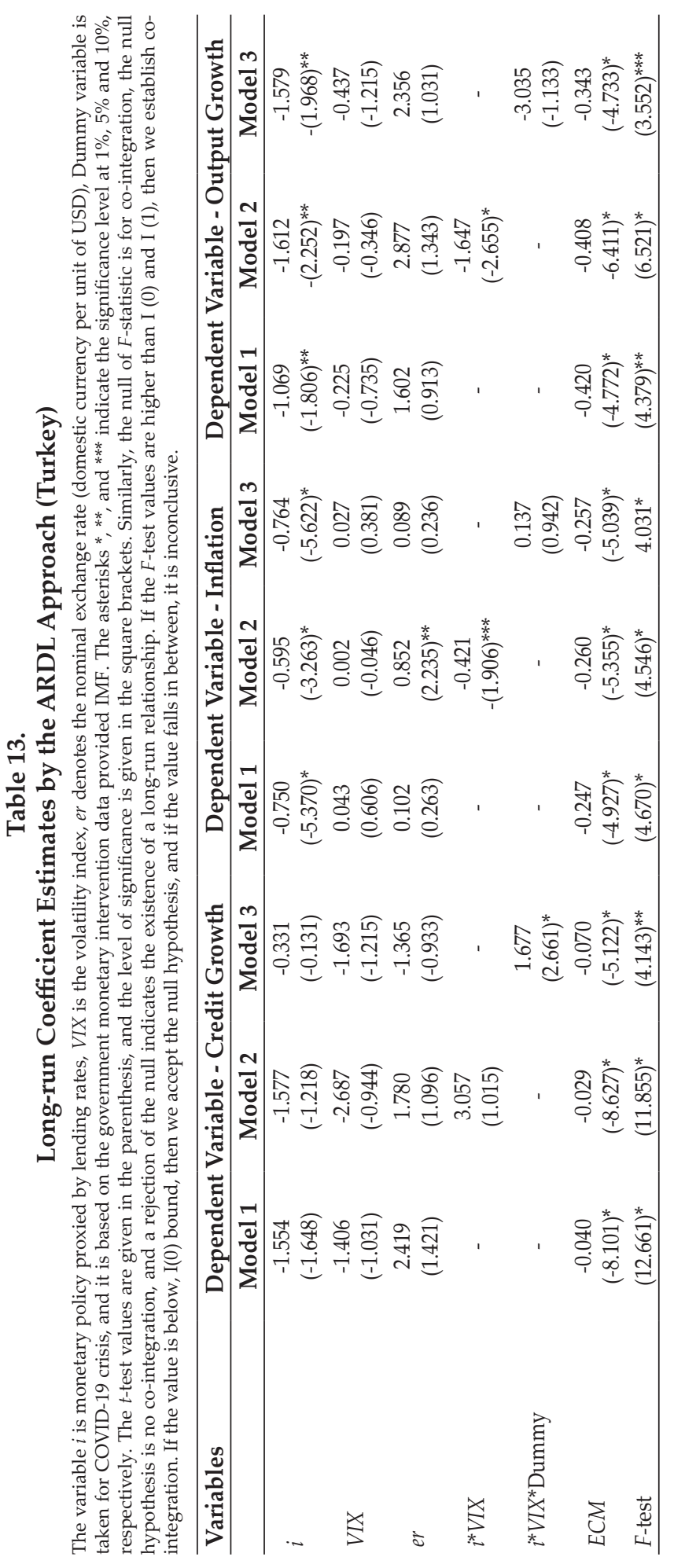




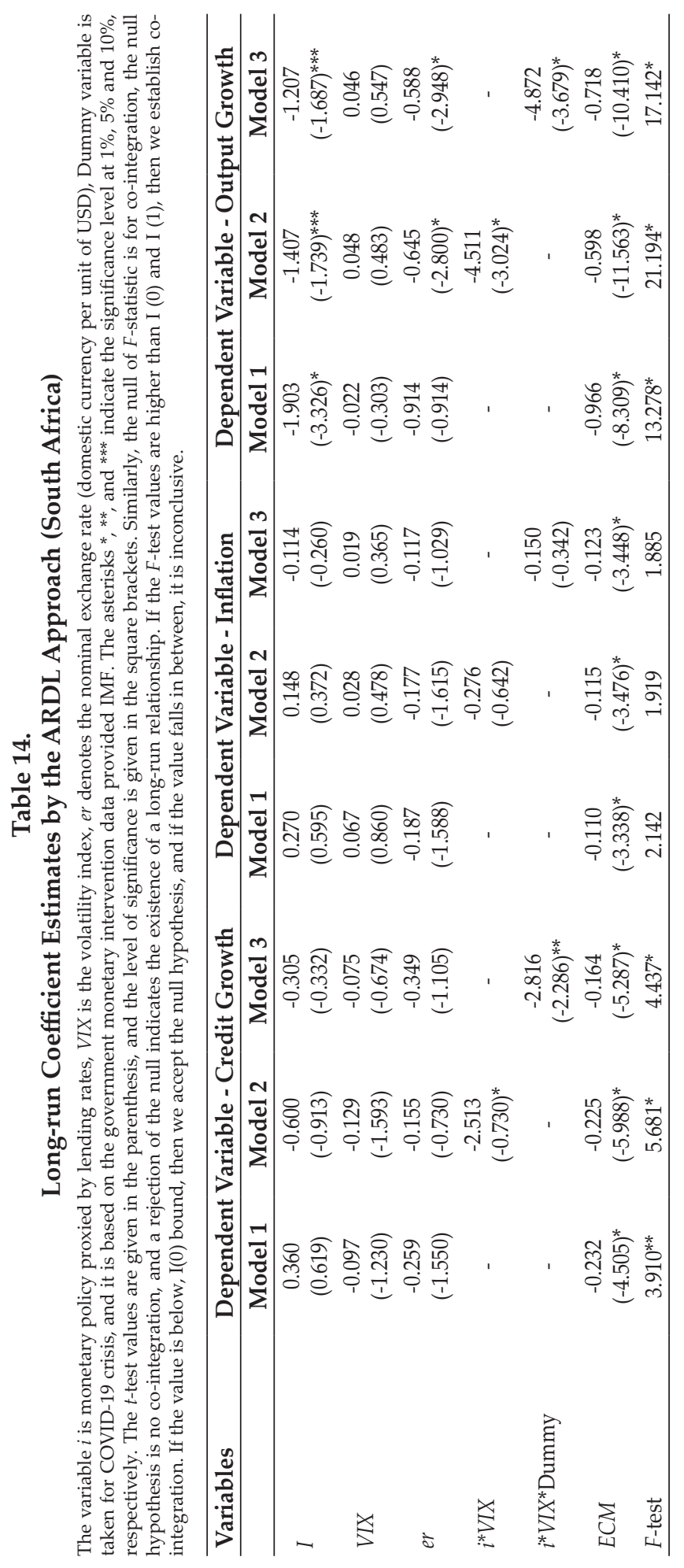




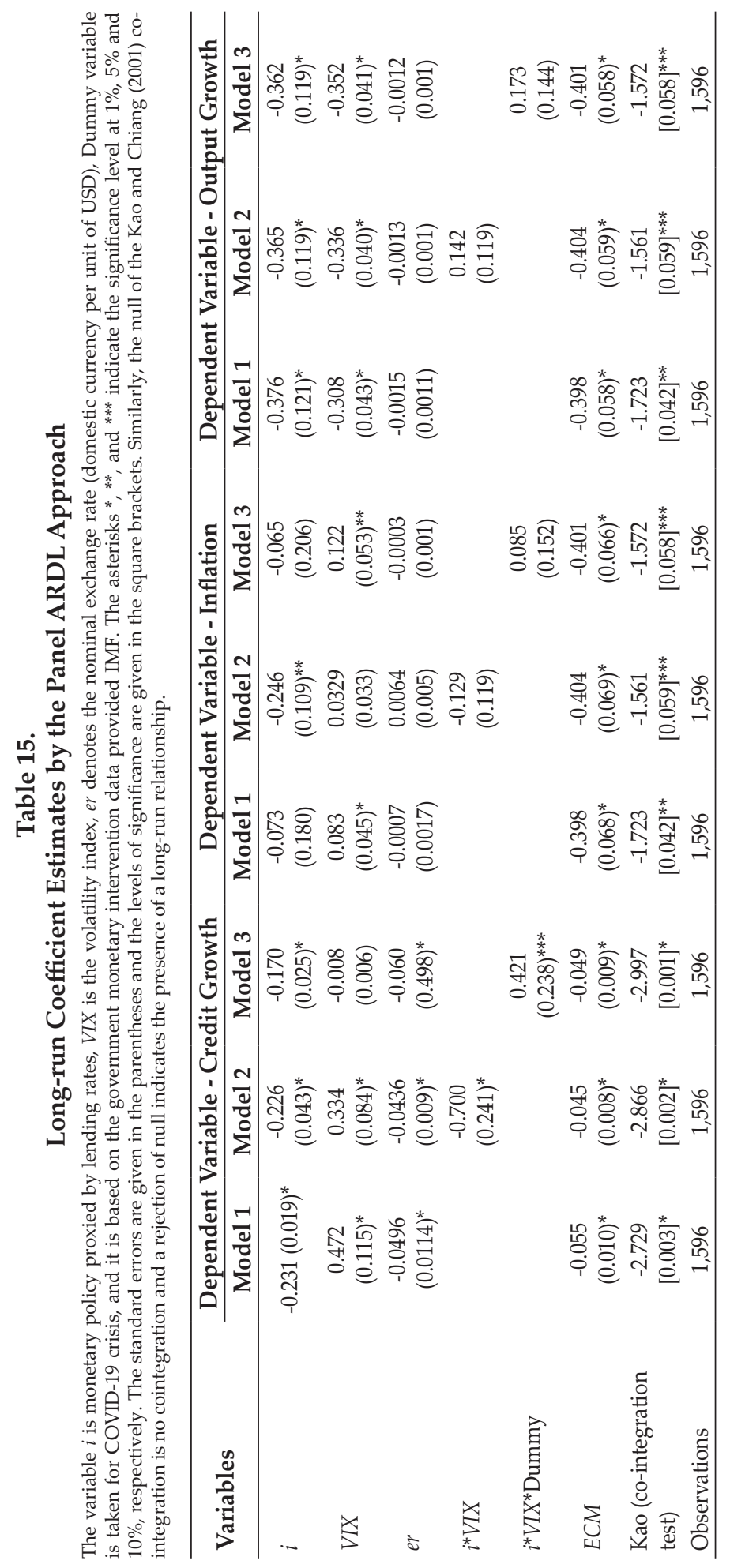




\section{B. Robustness Test}

In this section, we adopt an alternative estimation method to confirm the empirical findings from the time series framework. We carried out our estimations with the panel ARDL method proposed by Pesaran and Smith (1995) and Pesaran and Shin (1999). The long-run estimates are reported in the Table (15). It is interesting to note that the interaction variable $\left(i^{*} V I X\right)$ has a negative and significant effect on credit growth, indicating that monetary policy is effective in stabilizing credit growth during uncertainty. In contrast, this variable has no effect on inflation and output. Compared to output growth and inflation, the significant response of credit growth to interest rates may be attributed to the fact that the monetary transmission has a lag effect on the real sector, whereby credit changes occur earlier in responding to interest rate changes.

Similarly, the triple interaction term has a positive and significant effect on credit growth, in contrast to the expectation. In contrast, variable does not have any significant effect on inflation and output growth, which further confirms the weak monetary transmission during the COVID-19 induced uncertainty period. Thus, the overall findings from the panel estimation support our findings reported in the previous section.

\section{CONCLUSIONS}

This paper examined the effectiveness of the monetary policies of the emerging economies during the COVID-19 pandemic. It is argued in the literature that the effectiveness of monetary policy transmission is weak in the presence of uncertainty. Given the severe uncertainty induced by the COVID-19 pandemic, we examined the effectiveness of monetary policy transmission to output growth, inflation, and credit growth for fourteen EMEs that experienced the brunt of the pandemic. Using the ARDL approach to co-integration, we find that the COVID-19 induced uncertainty weakened the monetary policy transmission to inflation in most of these economies. However, in a few countries, monetary policy is found to be effective in stabilizing credit and output growth. Our overall findings suggest that the uncertainty created by COVID-19 induced economic agents to follow a 'wait and see' approach, making them less responsive to changes in monetary policy.

Our findings imply that monetary policy cannot stand alone in managing macroeconomic stability during periods of high uncertainty like the current pandemic. In this case, the integration of monetary and macroprudential policies needs to be strengthened in a policy mix strategy to support the effectiveness of monetary policy transmission and, at the same time, maintain macroeconomic stability (Warjiyo and Juhro, 2019; Juhro et al., 2021). In addition, as economic agents wait for precise information to respond to policy changes, credible communication from central banks is vital for effective monetary policy transmission. During uncertain times, the policymakers must act aggressively to stabilize the economy compared to the normal times. In other words, although monetary policy weakens during periods of uncertainty, inaction is not an option.

Our findings also have an implication for normalization policies in EMEs, namely ensuring uncertainty is already minimized to deliver effective monetary 
policy. Executing a tapering policy while there was still uncertainty related to the pandemic may not lead to the desired outcome. In the case of EMEs, uncertainty about the exit strategy in the developed economies also add to the level of uncertainty while the pandemic lasts. Therefore, policy communications of the developed economies to reduce uncertainty become crucial to ensuring effective monetary policy in EMEs.

\section{REFERENCE:}

Aastveit, K. A., Natvik, G. J., \& Sola, S. (2017). Economic Uncertainty and the Influence of Monetary Policy. Journal of International Money and Finance. http://dx.doi.org/10.1016/j.jimonfin.2017.05.003

Bhar, R., \& Malliaris, A. G. (2021). Modeling U.S. Monetary Policy During the Global Financial Crisis and Lessons for COVID-19. Journal of Policy Modeling, 43,15-33.

Bloom, N. (2009). The Impact of Uncertainty Shocks. Econometrica, 77, 623685.

Chundakkadan, R., \& Sasidharan, S. (2021). Monetary Policy Announcement and Stock Returns: Evidence from Long-term Repo Operations in India. Asian Economics Letters, 3(Early View). https://doi.org/10.46557/001c.27117

Devpura, N., \& Narayan, P. K. (2020). Hourly Oil Price Volatility: The Role of COVID-19. Energy Research Letters, 1. https://doi.org/10.46557/001c.13683

Dixit, A., \& Pindyck R. S. (1994). Investment Under Uncertainty. Princeton University Press.

Ehrmann, M., \& Smets, F. (2003). Uncertain Potential Output: Implications for Monetary Policy. Journal of Economic Dynamics and Control, 27, 1611-1638.

Giannoni, M. P. (2002). Does Model Uncertainty Justify Caution? Robust Optimal Monetary Policy in a Forward Looking Model. Macroeconomic Dynamics, 6, 111-144

Haroon, O., \& Rizvi, S. A. R. (2020). COVID-19: Media Coverage and Financial Markets Behavior-A Sectoral Inquiry. Journal of Behavioral and Experimental Finance, 27, 100343.

IMF. (2020). Central Bank Support to Financial Markets in the Coronavirus Pandemic, Special Series on COVID-19, Money and Capital Market, May 6, 2020, International Monetary Fund.

Iyke, B. N. (2020a). The Disease Outbreak Channel of Exchange Rate Return Predictability: Evidence from COVID-19. Emerging Markets Finance and Trade, 56, 2277-2297. https://doi.org/10.1080/1540496x.2020.1784718.

Iyke, B. N. (2020b). Economic policy uncertainty in times of COVID-19 pandemic. Asian Economics Letters, 1. https://doi.org/10.46557/001c.17665.

Iyke, B. N., \& Ho, S. Y. (2021). Exchange Rate Exposure in the South African Stock Market Before and During the COVID-19 Pandemic. Finance Research Letters, 102000. https://doi.org/10.1016/j.frl.2021.102000

Juhro, S. M., Prabheesh, K. P., \& Lubis, A. (2021), The Effectiveness of Trilemma Policy Choice in the Presence of Macroprudential Policies: Evidence from Emerging Economies, The Singapore Economic Review. https://doi.org/10.1142/S0217590821410058. 
Kao, C., \& Chiang, M. H. (2001). On the Estimation and Inference of a Cointegrated Regression in Panel Data", Baltagi, B. H., Fomby, T. B. and Carter Hill, R. (Ed.) Nonstationary Panels, Panel Cointegration, and Dynamic Panels (Advances in Econometrics, Vol. 15), Emerald Group Publishing Limited, Bingley, 179-222.

Levin, A. T., \& Sinha, A. (2020). Limitations on the Effectiveness of Monetary Policy Forward Guidance in the Context of the COVID-19 Pandemic. NBER Working Paper, 27748.

Li, X. (2021). Asymmetric Impact of COVID-19 on China's Stock Market Volatility: Media Effect or Fact? Asian Economics Letters, 2. https://doi.org/10.46557/001c.24143.

Martin, C., \& Milas, C. (2009). Uncertainty and Monetary Policy Rules in the United States. Economic Inquiry, 47, 206-215

Narayan, P. K. (2020). Oil Price News and COVID-19-Is There Any Connection? Energy Research Letters, 1. https://doi.org/10.46557/001c.13176

Narayan, P. K. (2021). COVID-19 Research Outcomes: An Agenda for Future Research. Economic Analysis and Policy, 71, 439-445.

Narayan, P. K., Devpura, N., \& Wang, H. (2020). Japanese Currency and Stock Market-What Happened During the COVID-19 Pandemic? Economic Analysis and Policy, 68, 191-198. http://dx.doi.org/10.1016/j.eap.2020.09.014.

OECD. (2020). Evaluating the Initial Impact of COVID Containment Measures on Activity. Technical Report, The Organisation for Economic Co-operation and Development.

Padhan, R., \& Prabheesh, K. P. (2021). The Economics of COVID-19 Pandemic: A Survey. Economic Analysis and Policy, 70, 220-237

Pellegrino, G. (2021). Uncertainty and Monetary Policy in the US: A Journey into Nonlinear Territory. Economic Inquiry, 59, 1106-1128.

Pesaran, M. H., \& Shin, Y. (1999). Pooled Mean Group Estimation of Dynamic Heterogeneous Panels. Journal of the American Statistical Association, 94, 621-634.

Pesaran, M. H., Shin, Y., \& Smith, R. P. (1999). An Autoregressive Distributed Lag Modelling Approach to Cointegration Analysis', in Storm, S. (ed.) Econometrics and Economic Theory in the 20th Cntury: The Ragnar Frisch Centennial Symposium, Chapter 11, Cambridge University Press, Cambridge.

Pesaran, M. H., \& Smith, R. (1995). Estimating Long-run Relationships from Dynamic Heterogeneous Panels. Journal of Econometrics, 68, 79-113

Phan, D. H. B., \& Narayan, P. K. (2020). Country Responses and the Reaction of the Stock Market to COVID-19-A Preliminary Exposition. Emerging Markets, Finance and Trade, 56, 2138-2150.

Rai, K., \& Garg, B. (2021). Dynamic Correlations and Volatility Spillovers between Stock Price and Exchange Rate in BRIICS Economies: Evidence from the COVID-19 Outbreak Period. Applied Economics Letters, 1-8.

Sonderstrom, U. (2002). Monetary Policy with Uncertain Parameters. The Scandinavian Journal of Economics, 104, 125-145.

Vidya, C. T. (2021). Has COVID-19 Shaken the World Trade and China's Preeminence? Asian Economics Letters, 3 (Early View). https://doi.org/10.46557/001c.25380. 
Vidya, C. T., \& Prabheesh, K. P. (2020). Implications of COVID-19 Pandemic on the Global Trade Networks. Emerging Markets, Finance and Trade, 56, 2408-2421. http://dx.doi.org/10.1080/1540496X.2020.1785426.

Warjiyo, P., \& Juhro, S. M. (2019). Central Bank Policy: Theory and Practice, Emerald Publishing Limited - London.

Wei, X., \& Han, L (2020). The Impact of COVID-19 Pandemic on Transmission of Monetary Policy to Financial Markets. International Review of Financial Analysis, 74, 101705.

Yilmazkuday, H. (2021). COVID-19 and Monetary Policy with Zero Bounds: A Cross-country Investigation. Finance Research Letters. https://doi.org/10.1016/j.frl.2021.102103.

Zainuddin, M. R. K. V., Khairuddin, N. A., \& Hamidi, H. N. A. (2021). Impact of COVID-19 on Malaysia's Bilateral Export: Testing for Heterogeneous Effects in the Product Category. Asian Economics Letters, 3 (Early View). https://doi.org/10.46557/001c.25386. 
This page is intentionally left blank 